\title{
Clinical utility of diagnostic guidelines and putative biomarkers in lymphangioleiomyomatosis
}

William YC Chang ${ }^{1}$, Jennifer L Cane ${ }^{1}$, John D Blakey ${ }^{2}$, Maruti Kumaran ${ }^{3}$, Kate S Pointon ${ }^{3}$ and Simon R Johnson ${ }^{\text {** }}$

\begin{abstract}
Background: Lymphangioleiomyomatosis is a rare disease occurring almost exclusively in women. Diagnosis often requires surgical biopsy and the clinical course varies between patients with no predictors of progression. We evaluated recent diagnostic guidelines, clinical features and serum biomarkers as diagnostic and prognostic tools.

Methods: Serum vascular endothelial growth factor-D (VEGF-D), angiotensin converting enzyme (ACE), matrix metalloproteinases (MMP) -2 and -9, clinical phenotype, thoracic and abdominal computerised tomography, lung function and quality of life were examined in a cohort of 58 patients. 32 healthy female controls had serum biomarkers measured.

Results: Serum VEGF-D, ACE and total MMP-2 levels were elevated in patients. VEGF-D was the strongest discriminator between patients and controls (median $=1174 \mathrm{vs.} 332 \mathrm{pg} / \mathrm{ml} \mathrm{p}<0.0001$ with an area under the receiver operating characteristic curve of $0.967,95 \%$ Cl 0.93-1.01). Application of European Respiratory Society criteria allowed a definite diagnosis without biopsy in 69\%. Adding VEGF-D measurement to ERS criteria further reduced the need for biopsy by 10\%. VEGF-D was associated with lymphatic involvement $(p=0.017)$ but not the presence of angiomyolipomas.
\end{abstract}

Conclusions: Combining ERS criteria and serum VEGF-D reduces the need for lung biopsy in LAM. VEGF-D was associated with lymphatic disease but not lung function.

Keywords: VEGF-D, Matrix metalloproteinase, Angiotensin converting enzyme, ERS LAM guidelines

\section{Background}

Lymphangioleiomyomatosis (LAM) is a rare lung disease which almost exclusively affects women and generally presents before the menopause [1,2]. It can occur sporadically or in association with the genetic condition tuberous sclerosis complex (TSC): both sporadic and TSC-LAM are associated with mutations in the TSC genes[3]. Histologically, LAM is characterised by the abnormal growth of atypical, smooth muscle-like LAM cells in the lungs leading to lung cysts, airway obstruction and in many cases, respiratory failure. Obstruction of axial lymphatics by LAM cells can cause lymphadenopathy and chylous collections[4]. In

\footnotetext{
* Correspondence: simon.johnson@nottingham.ac.uk

'Division of Therapeutics and Molecular Medicine, National Centre for Lymphangioleiomyomatosis and Nottingham Respiratory Biomedical Research Unit, D Floor, South Block, Queen's Medical Centre, University of Nottingham, Nottingham NG7 2UH, UK

Full list of author information is available at the end of the article
}

addition, around $60 \%$ of patients with sporadic LAM and most patients with TSC-LAM have one or more angiomyolipomas[5][6][7], benign tumours which share a common ancestry with pulmonary LAM cells [3,8-10]. Importantly, high resolution computerised tomography (HRCT) alone is not diagnostic of LAM and patients undergoing transplant for 'LAM' have been found to have other diseases after examination of the explanted lungs [11,12]. Lung biopsy is often used to confirm diagnosis, but recent clinical guidelines specify that a definitive diagnosis can be made without lung biopsy in the presence of lung cysts, plus evidence of either angiomyolipomas, chylous collections or TSC (Table 1) [13]. These diagnostic criteria, based on expert opinion, have not yet been formally evaluated. With the advent of disease specific treatments such as sirolimus [14,15] it is increasingly important to make the correct diagnosis. Furthermore, LAM is a variable disease with some patients 
Table 1 Summary of the ERS guidelines for the diagnosis of LAM

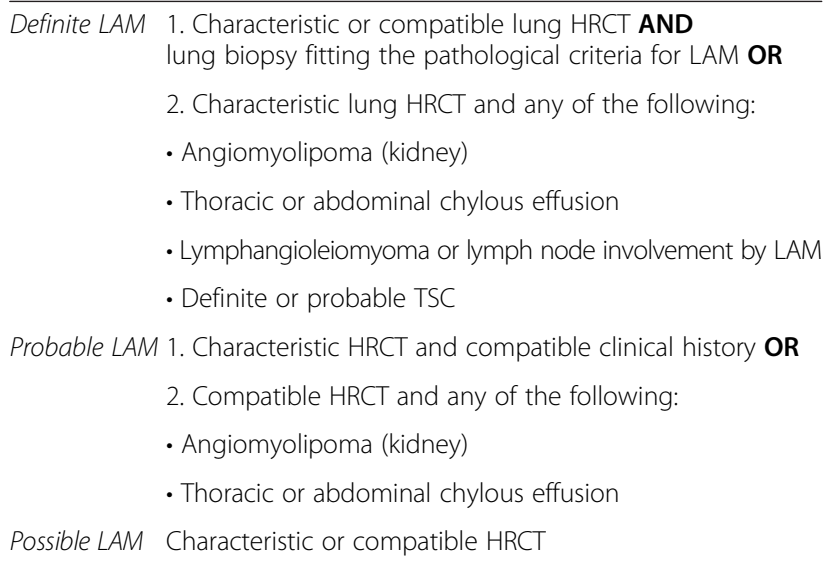

Possible LAM Characteristic or compatible HRCT

developing respiratory failure and others remaining stable for many years. It is currently not possible to predict with confidence the likely clinical course at presentation which is unsettling for patients and makes planning treatment difficult [16].

Circulating biomarkers offer a potential non-invasive method for aiding diagnosis, monitoring disease progression and predicting prognosis. Several putative biomarkers have already been identified in LAM. Vascular endothelial growth factor-D (VEGF-D), a ligand for the lymphatic growth-factor receptor VEGFR-3/Flt-4, is elevated in serum of patients with LAM compared with healthy volunteers and patients with other cystic lung diseases. The clinical utility of VEGF-D is not clear at present, however it has been suggested that a serum VEGF-D level of $>800 \mathrm{pg} / \mathrm{ml}$ in combination with typical cystic changes on HRCT is specific for LAM [17] though a VEGF-D level $<800 \mathrm{pg} / \mathrm{ml}$ does not exclude the diagnosis [18]. Matrix metalloproteinases (MMPs) are a family of enzymes involved in many processes including extracellular matrix remodelling, angiogenesis, migration and cell signalling $[19,20]$. Imbalance between MMPs and their inhibitors has been implicated in a variety of pulmonary disorders including LAM and elevated MMP-9, has been observed in the serum of LAM patients [21]. Finally, membrane bound ACE and other elements of the renin-angiotensin system have been identified in LAM cells by immunohistochemistry [22] and we have noted elevated serum angiotensin converting enzyme (ACE) in patients with LAM.

In order to determine if these clinical guidelines and biomarkers can improve clinical care for LAM patients by reducing the need for invasive diagnostic investigations and making more accurate predictions of prognosis, we have compared the clinical utility of serum VEGF-D, MMP-2, MMP-9 and ACE with the recent ERS diagnostic guidelines, health-related quality of life and clinical phenotype in a national cohort of patients with LAM.

\section{Methods}

\section{Subjects}

Patients were all receiving clinical care at the national referral centre for LAM in the UK. Patients were either participating in a clinical trial where baseline data were used, (NCT00989742, MHRA 03057/0032/001 -002, EUDRACT 2007-003745-32, NRES 07/H0403/165) or were in an observational cohort with Nottingham Ethics Committee approval (NRES 05/Q2403/187). All patients provided informed consent. Patients were classified as having either definite or probable LAM according to ERS consensus criteria (Table 1).

All were women over the age of 18 . Spirometry and transfer factor (TLCO) were measured according to ARTP/BTS standards [23]. Retrospective lung function results were obtained from clinical records. As short term observation of lung function reduces the accuracy of rate of decline estimates for $\mathrm{FEV}_{1}$ [16], serial data were used only when greater than three years of observation were available. Thoracic and abdominal HRCT were performed for the clinical trial or if indicated clinically. All patients had blood drawn for biomarker analysis. Full blood count, differential white cell count and C-reactive protein (CRP) were also measured to exclude intercurrent infection but were not part of the biomarker analysis. Participants in the clinical trial completed St George's Respiratory Questionnaires (SGRQ). Thirty two healthy control women over the age of 18 with no prior history of lung disease had blood taken for biomarker analysis (Nottingham University Ethics Committee approval BT A27 08 2009) with informed consent.

\section{Serum collection and storage}

Blood was collected in serum separator tubes, allowed to clot for 30 minutes at $4^{\circ} \mathrm{C}$, centrifuged at $4000 \mathrm{G}$ for 10 minutes and serum stored in aliquots at $-80^{\circ} \mathrm{C}$.

\section{VEGF-D, MMP-2, MMP-9 and ACE assays}

Serum VEGF-D and MMP-2 were measured using Quantikine Human VEGF-D and MMP-2 Immunoassays (R\&D Systems, Minneapolis, MN). Serum MMP-9 was measured using the Duoset Human MMP-9 Immunoassay (R\&D Systems) with a previously validated serum dilution of 1:1000 [24,25]. Serum ACE was determined by colourimetric assay based on hydrolysis of furylacryloylphenylalanylglycylglycine to furylacryloylphenylalanine and glycylglycine by serum ACE using an Olympus AU 2700 automated analyser (Olympus Diagnostics, Watford, UK).

\section{Interpretation of radiology}

CT scans were examined independently by two consultant radiologists (MK and KSP) blinded to other study data 
who scored "yes" or "no" to the presence or absence of lymphatic involvement and renal angiomyolipomas. Only a consensus between both radiologists was accepted. Cases where agreement was not reached were omitted from this part of the study.

\section{Statistical analysis}

Statistical analysis was performed using GraphPad Prism 5.02 (GraphPad Software, San Diego, California, USA) and SPSS 16 (SPSS Inc., Chicago, Illinois, USA). Comparison of age and biomarkers between groups was performed using the Mann-Whitney test and correlation between age and biomarkers was examined using Spearman's rho (statistical significance set at $\mathrm{p}<0.05$ for a 2tailed test). Predictive ability of serum biomarkers was assessed by receiver operator characteristic (ROC) curve analysis.

\section{Results}

\section{Characteristics of study subjects and application of ERS} criteria

Fifty eight patients were recruited. According to ERS criteria, 45 had definite and 13 had probable LAM [13]. Eight patients also had TSC. The 13 classified as probable LAM had a clinical history compatible with LAM, lung cysts on CT, but no extra-pulmonary features or evidence of TSC. 33/58 (57\%) presented with pneumothorax, 16/58 (28\%) with breathlessness alone, four with chylous collections and six incidentally after CT scans performed for unrelated problems. A lung biopsy had been performed for diagnosis in 22/58 patients. One or more angiomyolipomas defined radiologically or after histological analysis were present in $31 / 58$ patients (53\%). Patients were slightly older than control subjects (median age 46 yrs, interquartile range (IQR) 16.0 vs. 36 , IQR $12.3, \mathrm{p}=0.0003$ ) which was factored into the analysis. Only two controls and one patient had smoked.

Patients were taking standard therapy for LAM including bronchodilators and progesterone. Those taking sirolimus, doxycycline or post lung transplantation were excluded from the study. Only the 45 patients with definite LAM by ERS criteria were included in the comparison of biomarkers in LAM and controls: those with probable LAM were used to determine the utility of VEGF-D for diagnosis.

\section{Serum VEGF-D is significantly elevated in patients with LAM and is a better diagnostic marker than MMP-2, -9 and ACE}

Spearman correlation performed for age against serum VEGF-D, MMP-2, MMP-9 and ACE showed there was no significant correlation between age and biomarkers with the exception of MMP-2 $(\mathrm{p}=0.026)$. Serum VEGF-D $(\mathrm{p}<0.0001)$ ACE $(\mathrm{p}=0.006)$ and total MMP-2 $(\mathrm{p}=0.003)$ were higher in LAM when compared with controls (Figure 1). There was a trend toward higher total MMP-9 in patients with LAM, although this was not significant $(p=0.058)$. ROC analysis showed VEGF-D to be the strongest discriminator between those with LAM and controls (area under curve (AUC) $0.967 \pm 0.02$, 95\% CI 0.9271.007) when compared with ACE (AUC $0.671 \pm 0.069$, 95\% CI 0.538-0.805), MMP-2 (AUC 0.714 $\pm 0.064,95 \%$ CI 0.590-0.839) and MMP-9 (AUC $0.641 \pm 0.069$, 95\% CI $0.505-0.777$ ) (Figure 1). The sensitivity and specificity of VEGF-D were $56 \%$ and $100 \%$ respectively with a positive predictive value of $100 \%$ and a negative predictive value of $61 \%$ using a cut off of $800 \mathrm{pg} / \mathrm{ml}$. In our cohort, a value of $440 \mathrm{pg} / \mathrm{ml}$ was the optimal discriminative point, correctly assigning all but 4 cases and all but 1 control. Of the patients with definite LAM by current ERS criteria, $42 \%$ had a VEGF-D of less than $800 \mathrm{pg} / \mathrm{ml}$. To examine if VEGF-D was stable over time, we examined serum VEGF$\mathrm{D}$ over a one year period. The mean baseline level was $1522 \mathrm{pg} / \mathrm{ml}$ (SD 1156). For the three month period where most data were available, there was a $10 \%$ rise in VEGF-D $(\mathrm{n}=19$ patients, mean rise $158 \mathrm{pg} / \mathrm{ml}$, SD 254). Over this period, none with raised VEGF-D fell below $800 \mathrm{pg} / \mathrm{ml}$ but one patient with a borderline level at baseline increased above the $800 \mathrm{pg} / \mathrm{ml}$ diagnostic threshold (Figure 2).

Utility of the ERS criteria combined with VEGF-D for the identification of LAM in patients with cystic lung disease As VEGF-D was the most sensitive and specific diagnostic marker we examined whether measurement of serum VEGF-D could reduce the need for lung biopsy in patients with suspected LAM and how VEGF-D measurement contributed to diagnosis as defined by the recent ERS criteria. To do this, patients were reclassified into either 'definite' or 'probable' LAM according to ERS criteria but without reference to information from lung biopsy. Application of ERS criteria, without biopsy information, allowed a definite diagnosis of LAM in 40 of 58 patients (69\%) without the need for biopsy. Interestingly 17 of these 40 had had a lung biopsy, all of which confirmed LAM. Of the remaining 18 patients where ERS criteria could not make a definite diagnosis without lung biopsy, six of these had a VEGF-D level of $>800 \mathrm{pg} / \mathrm{ml}$ suggesting a further $10 \%$ of patients could avoid lung biopsy for a definite diagnosis of LAM were this criteria to be added to diagnostic guidelines (Figure 3).

\section{Association of serum biomarkers with lung function parameters}

We next examined if these biomarkers were related to disease severity. VEGF-D, ACE and MMP-9 levels were not associated with percent predicted or absolute $\mathrm{FEV}_{1}$ or TLCO. Surprisingly, a higher total MMP-2 was associated with both better $\mathrm{FEV}_{1}(\mathrm{p}=0.01)$ and TLCO $(\mathrm{p}=0.02)$ using 

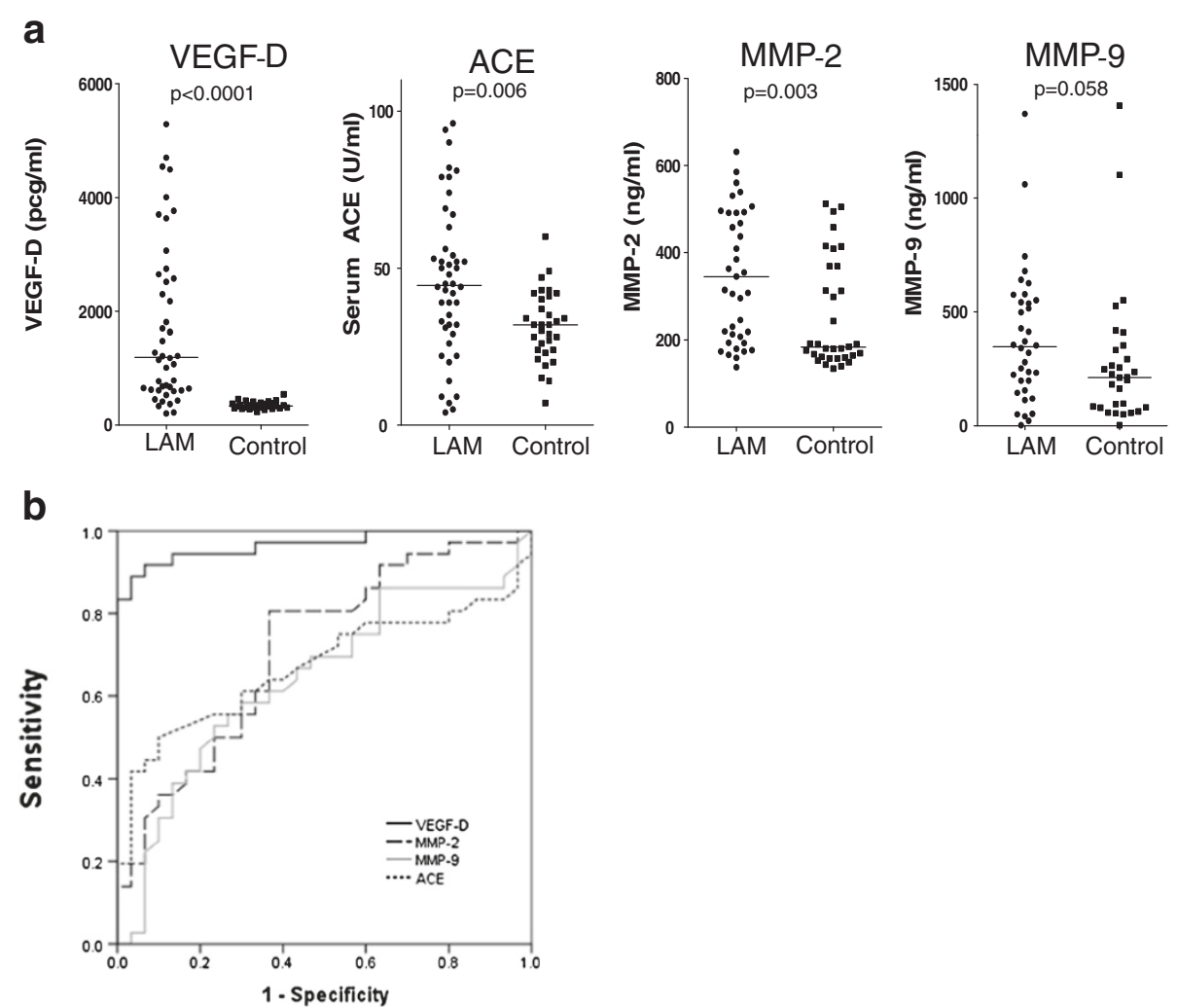

Figure 1 Biomarker levels in patients with LAM and controls. (a) Scatter plots comparing patients with definite LAM and controls for: VEGF-D, ACE, MMP-2 and MMP-9. All $p$ values were calculated using Mann-Whitney test and corrected for age. Horizontal lines are the group means. (b) Receiver operating characteristic curves for VEGF-D, ACE, MMP-2 and MMP-9.

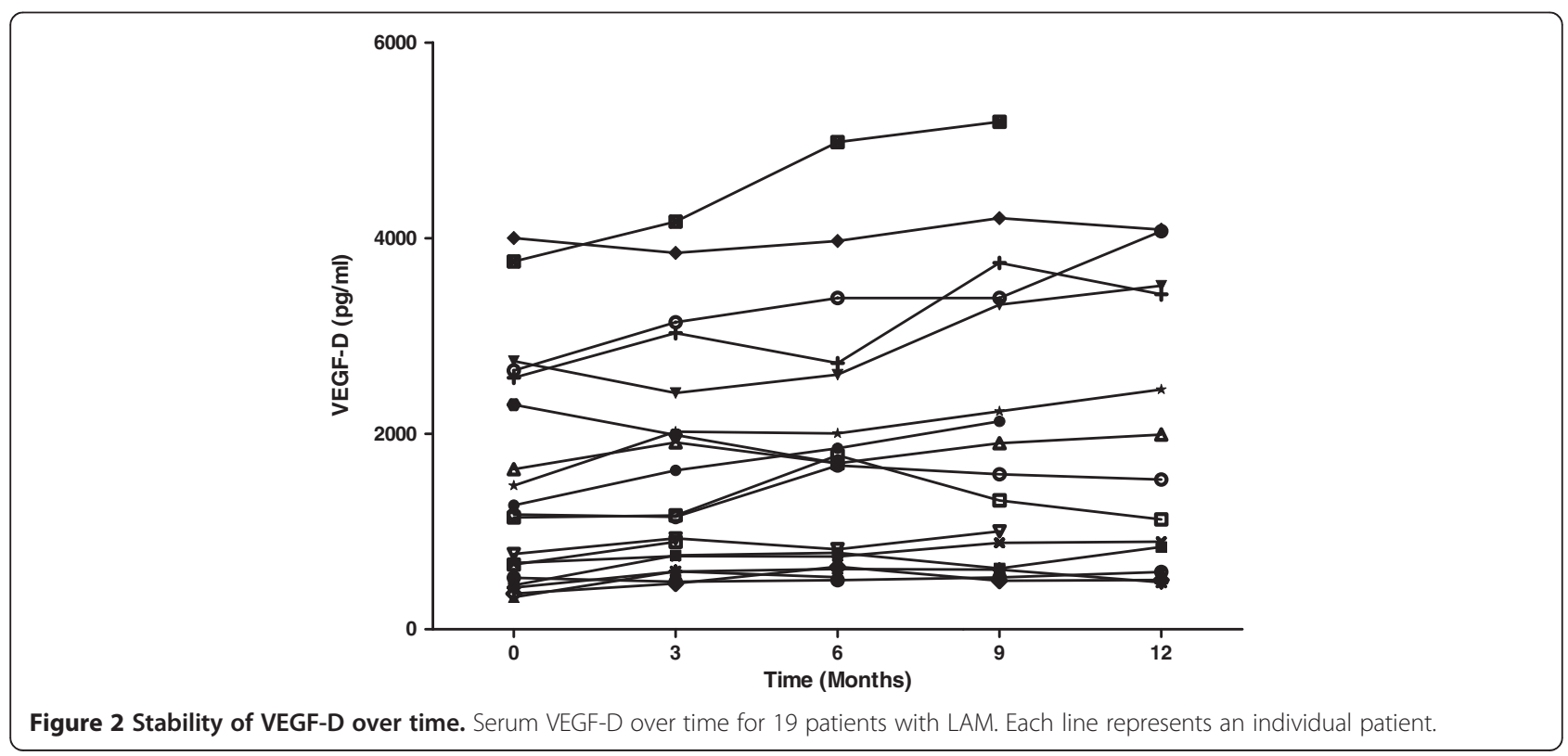



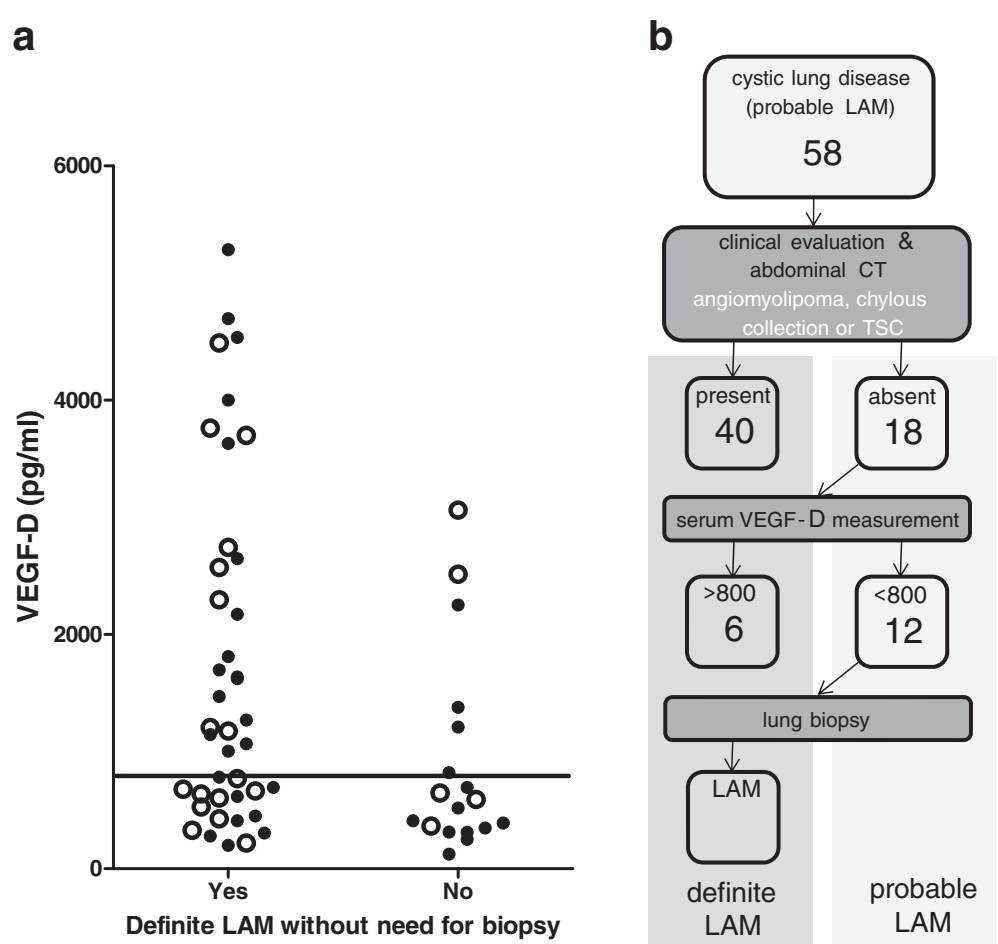

Figure 3 Analysis of diagnostic utility of VEGF-D. (a) Patients are classified based on whether a definite diagnosis of LAM using ERS criteria can be made without reference to biopsy data. Open circles indicate those patients who underwent lung biopsy all of whom were confirmed to have LAM by histological analysis. Solid line shows the proposed cut off of $800 \mathrm{pg} / \mathrm{ml}$ VEGF-D used to support the diagnosis of LAM. (b) Algorithm using diagnostic strategy based upon application of ERS criteria with the inclusion of serum VEGF-D measurement prior to lung biopsy. Figure shows the number from the initial 58 patients in whom a definite diagnosis of LAM can be made at each stage.

Spearman 2 tailed correlation whether actual or percent predicted values were considered (Figure 4. ACE and MMP-9 data not shown). A generalized linear model with $\mathrm{FEV}_{1}$ percent predicted as the dependent variable and age and biomarkers as covariates confirmed the association with MMP-2 ( $=0.0023)$, within the limits of our relatively small sample size.

To determine if VEGF-D is associated with disease activity rather than extent of lung function abnormality at a single time point we tested if those with higher VEGF-D experienced a more rapid decline in $\mathrm{FEV}_{1}$. Historical lung function data of greater than three years duration were available for 19 patients. The overall rate of decline in $\mathrm{FEV}_{1}$ calculated by linear regression was $113 \mathrm{ml} /$ year (range 28 $-461 \mathrm{ml} /$ year). Rate of $\mathrm{FEV}_{1}$ decline in individuals was not associated with VEGF-D level ( $\mathrm{p}=0.48$, Spearman's Rho).

\section{VEGF-D is a marker for lymphatic involvement but not angiomyolipomas}

As VEGF-D is a lymphangiogenic protein we examined if patients with lymphatic involvement had higher levels of VEGF-D than other patients. In the 29 patients for whom abdominal CT data were available, those with lymphatic involvement had higher VEGF-D levels than those who did not $(\mathrm{p}=0.004)$. VEGF-D was not associated with the presence of angiomyolipomas (Figure 5).

\section{Quality of life is associated with lung function}

Median overall score for the SGRQ was 30.86 (IQR 36.21) and higher overall score was associated with lower percent predicted $\mathrm{FEV}_{1}\left(\mathrm{R}^{2}=0.533, \mathrm{p}=0.0003\right)$ and TLCO $\left(\mathrm{R}^{2}=0.499\right.$, $\mathrm{p}=0.0005$ ) (Figure 6). Similar findings were seen with the component scores of symptoms, activity and impact (data not shown).

\section{Discussion}

In this study we evaluated the diagnostic utility of the recent ERS LAM guidelines and clinical use of four serum biomarkers. After prospective application of the ERS criteria to a national cohort, only $30 \%$ of these patients remained without a definite diagnosis and this could be reduced to $20 \%$ by adding a VEGF-D level of $>800 \mathrm{pg} / \mathrm{ml}$. Our data confirm the finding that VEGF-D is elevated in LAM $[18,26]$ and in our cohort, has a diagnostic specificity of $100 \%$ but a sensitivity of only $56 \%$ : suggesting that an elevated VEGF-D is helpful in confirming the diagnosis of LAM, but a normal VEGF-D level is not sufficient to exclude it. We also show that VEGF-D 

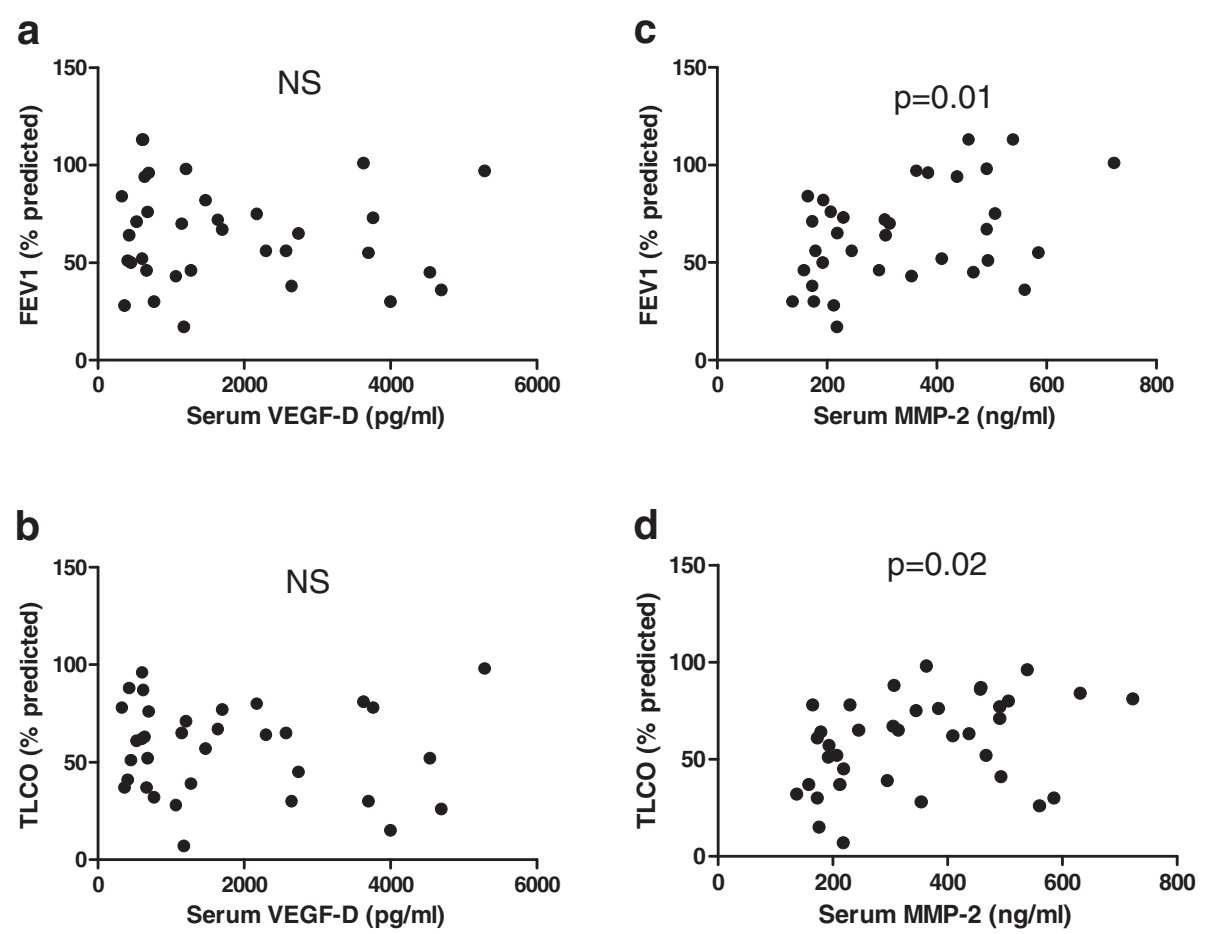

Figure 4 Correlation of biomarkers with lung function. VEGF-D levels are not correlated with (a) percent predicted FEV or $_{1}$ (b) percent predicted TLCO. (c) serum MMP-2 levels are associated with percent predicted FEV ${ }_{1}$ and (d) percent predicted TLCO.
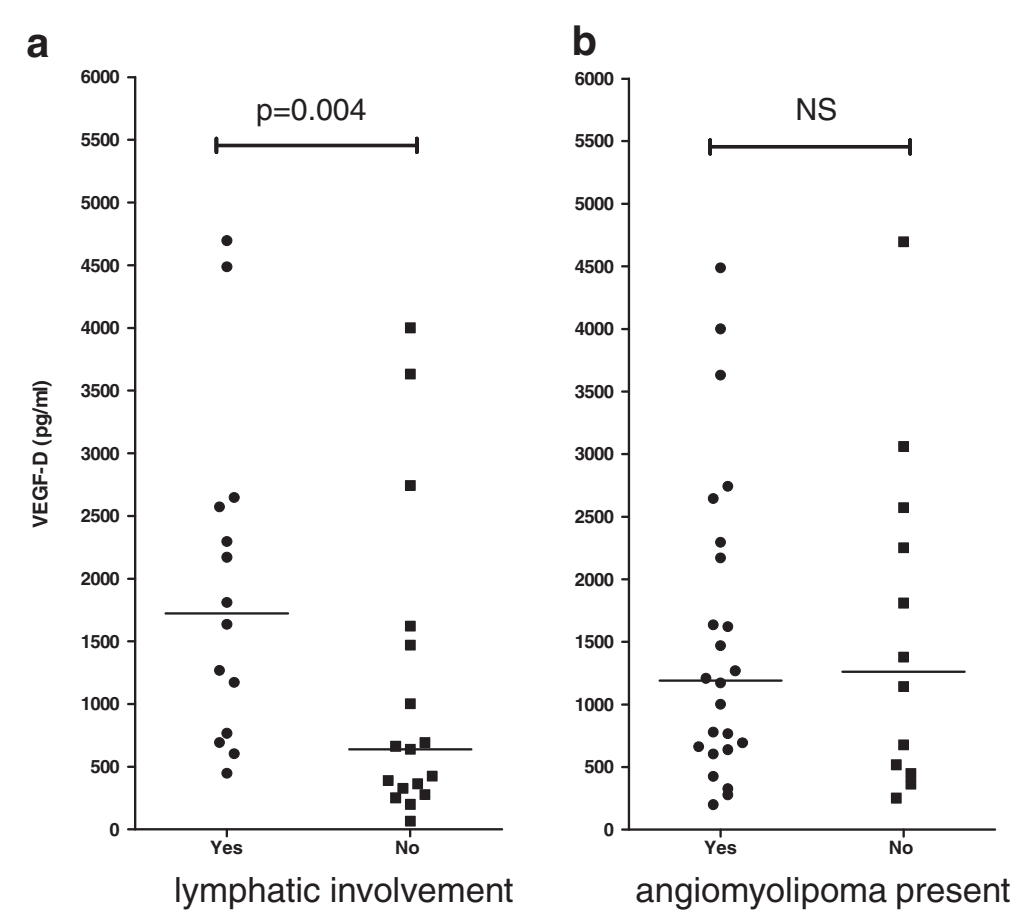

Figure 5 Association of VEGF-D with lymphatic involvement and angiomyolipomas. VEGF-D level is associated with (a) lymphatic involvement but not (b) the presence of angiomyolipomas. (Mann-Whitney test). 


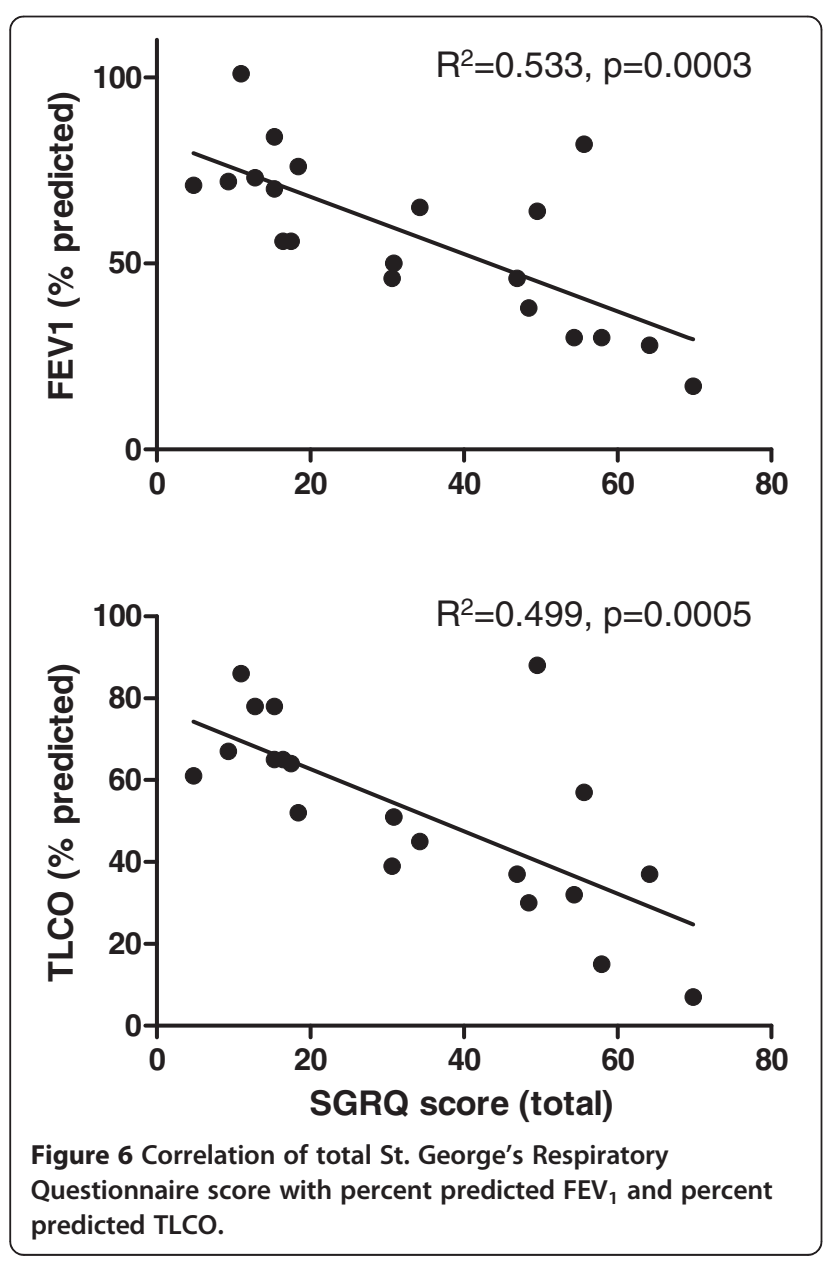

levels are relatively constant in individuals over time, which improves confidence in the measurement. Although not evaluated here, importantly, Young et al. [17] have demonstrated that VEGF-D can also discriminate between LAM and the other cystic diseases, pulmonary Langerhans cell histiocytosis, Birt Hogg Dubé disease and emphysema. The value that best classified subjects into either the LAM or healthy control group was $440 \mathrm{pg} / \mathrm{ml}$ in this cohort, this value is lower than that reported by Young et al., probably due to the use of healthy women as our control population. Taken together, our findings suggest that increased knowledge and application of the ERS diagnostic criteria amongst respiratory physicians could reduce the use of lung biopsy in suspected LAM and this could be improved further by incorporating VEGF-D measurement into the diagnostic workup. The observation that VEGF-D is associated with lymphatic disease rather than lung function decline or other aspects of disease activity or phenotype is consistent with a recent clinical trial where VEGF-D in patients with LAM was suppressed by inhibition of the mTOR pathway but did not parallel changes in lung function [15].
In contrast to Odajima et al. [21] we found that serum MMP-2 is significantly elevated in LAM. The finding of raised MMP-2 in LAM patient serum is consistent with the observation that LAM derived cells in culture produce excess amounts of MMP-2 which may have therapeutic implications if the protein is activated locally in LAM lesions $[27,28]$. It is unclear why better lung function is associated with a higher MMP-2 level, although it is unlikely to be an artefact as this was consistent for both $\mathrm{FEV}_{1}$ and TLCO. It is possible that MMP-2 production may fall in advanced disease or conversely, MMP- 2 may be a protective mechanism against lung destruction. Although MMP-2 and -9 were not useful as diagnostic or prognostic indicators, it remains to be seen whether MMP inhibition will affect disease progression in LAM and the role of MMP-2 requires particular investigation.

The presence of angiotensinogen, angiotensin II, receptors for angiotensin II and ACE in LAM lung tissue has been described by Valencia et al. [22] and it has been postulated that a LAM specific renin-angiotensin system may play a role in LAM cell proliferation and migration. Our observation that serum ACE is increased in LAM would be consistent with several possibilities, including release of ACE from LAM cells, cleavage of membrane bound ACE, again, possibly by MMPs [29], or a result of secondary changes to the cardiovascular system in response to the burden of cystic lung disease. The relatively poor separation of ACE levels between patients and controls make this measurement unhelpful as a diagnostic tool.

The overall composite score of the SGRQ and the components relating to symptoms, activity and impact correlated well with percent predicted $\mathrm{FEV}_{1}$ and TLCO in keeping with other studies [2,30]. It remains to be seen whether the SGRQ will add any further information above lung function measurements but it deserves evaluation as a marker of treatment response in clinical trials.

Certain caveats apply to the study. Despite this being a relatively large and detailed study for a rare disease, absolute numbers are small for some aspects of the analysis. Also the lung function decline data is retrospective and needs to be repeated in a prospective study. Our patient group encompassed approximately one third of all patients within the country and included the full spectrum of patients from those with no symptoms to those being evaluated for pulmonary transplantation. The cohort is similar to other cohorts with respect to age at presentation and rate of decline in lung function and we feel this makes our findings applicable to a range of patients being evaluated for possible LAM. 


\section{Conclusions}

Of the biomarkers examined, serum VEGF-D alone had a sufficient positive predictive value for use as a diagnostic test for LAM. When used in combination with the ERS diagnostic criteria $80 \%$ of patients could avoid lung biopsy for diagnosis. Total MMP-2 was elevated in LAM patients although the significance of these observations needs further investigation at a mechanistic level. With the exception of total MMP-2, no serum biomarker was associated with lung function or disease activity. The SGRQ correlates well with $\mathrm{FEV}_{1}$ and TLCO in patients with LAM and may be a useful assessment tool, particularly in those who find pulmonary function tests difficult. Its role as an endpoint in an interventional study should be evaluated.

\section{Author contribution \\ WYCC recruited patients, performed some assays, analysed the data and wrote some of the manuscript. JLC contributed to the biomarker measurements and data analysis, MK and KSP evaluated all radiology and contributed to data analysis, JB performed the statistical modelling and helped with data analysis. SRJ conceived and designed the study, participated in its coordination, data analysis and co-wrote the manuscript. All authors have read and approved the final manuscript.}

\section{Funding}

The study was funded by the British Lung Foundation, LAM Action and the Nottingham Respiratory Biomedical Research Unit.

\section{Author details}

'Division of Therapeutics and Molecular Medicine, National Centre for Lymphangioleiomyomatosis and Nottingham Respiratory Biomedical Research Unit, D Floor, South Block, Queen's Medical Centre, University of Nottingham, Nottingham NG7 2UH, UK. ${ }^{2}$ Division of Respiratory Medicine, University of Nottingham and Nottingham Respiratory Biomedical Research Unit, City Hospital, Nottingham NG5 1 PB, UK. ${ }^{3}$ Department of Radiology, Nottingham University Hospitals NHS Trust, Nottingham NG7 2UH, UK.

Received: 21 January 2012 Accepted: 18 April 2012

Published: 18 April 2012

\section{References}

1. Johnson S: Rare diseases. 1. Lymphangioleiomyomatosis: clinical features, management and basic mechanisms. Thorax 1999, 54:254-264.

2. Ryu JH, Moss J, Beck GJ, Lee J-C, Brown KK, Chapman JT, Finlay GA, Olson EJ, Ruoss SJ, Maurer JR, et al: The NHLBI Lymphangioleiomyomatosis registry: characteristics of 230 Patients at Enrollment. Am J Respir Crit Care Med 2006, 173:105-111.

3. Carsillo T, Astrinidis A, Henske EP: Mutations in the tuberous sclerosis complex gene TSC2 are a cause of sporadic pulmonary lymphangioleiomyomatosis. Proc Natl Acad Sci USA 2000, 97:6085-6090.

4. Johnson SR: Lymphangioleiomyomatosis. Eur Respir J 2006, 27:1056-1065.

5. Bernstein SM, Newell JD Jr, Adamczyk D, Mortenson RL, King TE Jr: Lynch DA: How common are renal angiomyolipomas in patients with pulmonary lymphangiomyomatosis?. Am J Respir Crit Care Med 1995, 152:2138-2143.

6. Matsui K, Tatsuguchi A, Valencia J, Yu Z, Bechtle J, Beasley MB, Avila N, Travis WD, Moss J, Ferrans VJ: Extrapulmonary lymphangioleiomyomatosis (LAM): clinicopathologic features in 22 cases. Hum Pathol 2000, 31:1242-1248.

7. Rakowski SK, Winterkorn EB, Paul E, Steele DJ, Halpern EF, Thiele EA: Renal manifestations of tuberous sclerosis complex: Incidence, prognosis, and predictive factors. Kidney Int 2006, 70:1777-1782.
8. Sato T, Seyama K, Fujii H, Maruyama H, Setoguchi Y, Iwakami S, Fukuchi Y, Hino O: Mutation analysis of the TSC1 and TSC2 genes in Japanese patients with pulmonary lymphangioleiomyomatosis. J Hum Genet 2002, 47:20-28.

9. Yu J, Astrinidis A, Henske EP: Chromosome 16 loss of heterozygosity in tuberous sclerosis and sporadic lymphangiomyomatosis. Am J Respir Crit Care Med 2001, 164:1537-1540.

10. Colombat M, Boccon-Gibod L, Carton S: An unusual renal angiomyolipoma with morphological lymphangioleiomyomatosis features and coexpression of oestrogen and progesterone receptors. Virchows Arch 2002, 440:102-104.

11. Mahadeva R, Stewart S, Wallwork J: Metastatic endometrial stromal sarcoma masquerading as pulmonary lymphangioleiomyomatosis. J Clin Pathol 1999, 52:147-148.

12. Colombat M, Stern M, Groussard O, Droz D, Brauner M, Valeyre D, Mal H, Taille C, Monnet I, Fournier M, et al: Pulmonary cystic disorder related to light chain deposition disease. Am J Respir Crit Care Med 2006, 173:777-780.

13. Johnson SR, Cordier JF, Lazor R, Cottin V, Costabel U, Harari S, ReynaudGaubert M, Boehler A, Brauner M, Popper H, et al: European Respiratory Society guidelines for the diagnosis and management of lymphangioleiomyomatosis. Eur Respir J 2010, 35:14-26.

14. Davies DM, Johnson SR, Tattersfield AE, Kingswood JC, Cox JA, McCartney DL, Doyle T, Elmslie F, Saggar A, de Vries PJ, Sampson JR: Sirolimus therapy in tuberous sclerosis or sporadic lymphangioleiomyomatosis. $N$ Engl J Med 2008, 358:200-203.

15. McCormack FX, Inoue $Y$, Moss J, Singer LG, Strange C, Nakata K, Barker AF, Chapman JT, Brantly ML, Stocks JM, et al: Efficacy and Safety of Sirolimus in Lymphangioleiomyomatosis. N Engl I Med 2011, 364:1595-1606.

16. Johnson SR, Tattersfield AE: Decline in Lung Function in Lymphangioleiomyomatosis. Relation to Menopause and Progesterone Treatment. Am J Respir Crit Care Med 1999, 160:628-633.

17. Young $L R$, Vandyke R, Gulleman PM, Inoue $Y$, Brown KK, Schmidt LS, Linehan WM, Hajjar F, Kinder BW, Trapnell BC, et al: Serum vascular endothelial growth factor-D prospectively distinguishes lymphangioleiomyomatosis from other diseases. Chest 2010, 138:674-681.

18. Glasgow CG, Avila NA, Lin JP, Stylianou MP, Moss J: Serum vascular endothelial growth factor-D levels in patients with lymphangioleiomyomatosis reflect lymphatic involvement. Chest 2009, 135:1293-1300.

19. Greenlee KJ, Werb Z, Kheradmand F: Matrix metalloproteinases in lung: multiple, multifarious, and multifaceted. Physiol Rev 2007, 87:69-98.

20. Visse R, Nagase H: Matrix metalloproteinases and tissue inhibitors of metalloproteinases: structure, function, and biochemistry. Circ Res 2003, 92:827-839.

21. Odajima N, Betsuyaku T, Nasuhara Y, Inoue H, Seyama K, Nishimura M: Matrix metalloproteinases in blood from patients with LAM. Respir Med 2009, 103:124-129.

22. Valencia JC, Pacheco-Rodriguez G, Carmona AK, Xavier J, Bruneval P, Riemenschneider WK, Ikeda Y, Yu ZX, Ferrans VJ, Moss J: Tissue-specific renin-angiotensin system in pulmonary lymphangioleiomyomatosis. Am J Respir Cell Mol Biol 2006, 35:40-47.

23. Bush A, Cramer D: Guidelines for the measurement of respiratory function. Respir Med 1994, 88:798.

24. McCann CJ, Glover BM, Menown IB, Moore MJ, McEneny J, Owens CG, Smith B, Sharpe PC, Young IS, Adgey JA: Novel biomarkers in early diagnosis of acute myocardial infarction compared with cardiac troponin T. Eur Heart J 2008, 29:2843-2850.

25. Kuenz B, Lutterotti A, Ehling R, Gneiss C, Haemmerle M, Rainer C, Deisenhammer F, Schocke M, Berger T, Reindl M: Cerebrospinal fluid B cells correlate with early brain inflammation in multiple sclerosis. PLoS One 2008, 3:e2559.

26. Young $L R$, Inoue $Y$, McCormack FX: Diagnostic potential of serum VEGF-D for lymphangioleiomyomatosis. N Engl J Med 2008, 358:199-200.

27. Hayashi T, Fleming MV, Stetler-Stevenson WG, Liotta LA, Moss J, Ferrans VJ, Travis WD: Immunohistochemical study of matrix metalloproteinases (MMPs) and their tissue inhibitors (TIMPs) in pulmonary lymphangioleiomyomatosis (LAM). Hum Pathol 1997, 28:1071-1078.

28. Lee PS, Tsang SW, Moses MA, Trayes-Gibson Z, Hsiao LL, Jensen R, Squillace R, Kwiatkowski DJ: Rapamycin-insensitive up-regulation of MMP2 and other genes in tuberous sclerosis complex 2-deficient lymphangioleiomyomatosis-like cells. Am J Respir Cell Mol Biol 2009, 42:227-234. 
29. Ramchandran R, Kasturi S, Douglas JG, Sen I: Metalloprotease-mediated cleavage secretion of pulmonary ACE by vascular endothelial and kidney epithelial cells. Am J Physiol 1996, 271:H744-H751.

30. Wang L, Tian XL, Gui YS, Peng M, Cai BQ, Zhu YJ: The St. George's Respiratory Questionnaire in lymphangioleiomyomatosis. Chin Med Sci J 2010, 25:140-145.

doi:10.1186/1465-9921-13-34

Cite this article as: Chang et al:: Clinical utility of diagnostic guidelines and putative biomarkers in lymphangioleiomyomatosis. Respiratory

Research 2012 13:34.

\section{Submit your next manuscript to BioMed Central and take full advantage of:}

- Convenient online submission

- Thorough peer review

- No space constraints or color figure charges

- Immediate publication on acceptance

- Inclusion in PubMed, CAS, Scopus and Google Scholar

- Research which is freely available for redistribution 